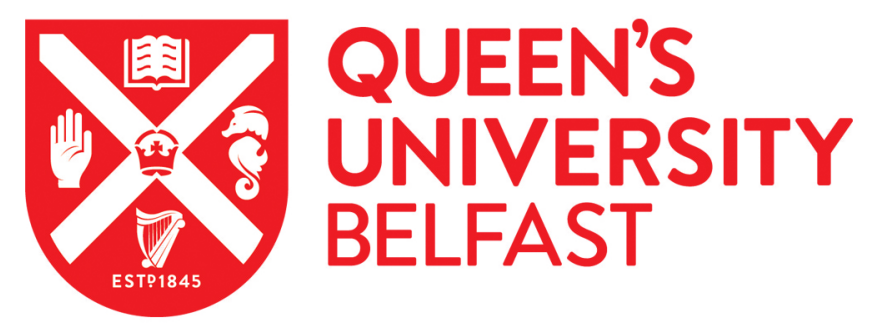

\title{
Using the Adolescent Time Inventory-Time Attitudes (ATI-TA) to assess time attitudes in Italian adolescents and young adults: Psychometric properties and validity
}

Donati, M. A., Boncompagni, J., Scabia, A., Morsanyi, K., \& Primi, C. (2018). Using the Adolescent Time Inventory-Time Attitudes (ATI-TA) to assess time attitudes in Italian adolescents and young adults: Psychometric properties and validity. INTERNATIONAL JOURNAL OF BEHAVIORAL DEVELOPMENT.

https://doi.org/10.1177/0165025418797020

Published in:

INTERNATIONAL JOURNAL OF BEHAVIORAL DEVELOPMENT

Document Version:

Peer reviewed version

Queen's University Belfast - Research Portal:

Link to publication record in Queen's University Belfast Research Portal

\section{Publisher rights}

(C) 2018 The Authors. This work is made available online in accordance with the publisher's policies. Please refer to any applicable terms of use of the publisher.

\section{General rights}

Copyright for the publications made accessible via the Queen's University Belfast Research Portal is retained by the author(s) and / or other copyright owners and it is a condition of accessing these publications that users recognise and abide by the legal requirements associated with these rights.

Take down policy

The Research Portal is Queen's institutional repository that provides access to Queen's research output. Every effort has been made to ensure that content in the Research Portal does not infringe any person's rights, or applicable UK laws. If you discover content in the

Research Portal that you believe breaches copyright or violates any law, please contact openaccess@qub.ac.uk. 
Using the Adolescent Time Inventory-Time Attitudes (ATI-TA) to assess time attitudes in Italian adolescents and young adults: Psychometric properties and validity

Maria Anna Donati, Jessica Boncompagni, Aurora Scabia, Kinga Morsanyi ${ }^{\circ}$, \& Caterina Primi

RUNNING HEAD: MEASURING TIME ATTITUDES IN YOUNG PEOPLE

Department of Neuroscience, Psychology, Drug, and Child's Health (NEUROFARBA), Section of Psychology, University of Florence, Italy.

${ }^{\circ}$ School of Psychology, Queens University of Belfast, Belfast, UK.

Correspondence concerning this article should be addressed to Maria Anna Donati, Department of Neuroscience, Psychology, Drug, and Child's Health (NEUROFARBA), Section of Psychology, via di San Salvi 12- Padiglione 26, 50135 Firenze (Italy). E-mail:

$\underline{\text { mariaanna.donati@unifi.it }}$

Please cite the paper as:

Donati, M. A., Boncompagni, J., Scabia, A., Morsanyi, K. \& Primi, C. (2018). Using the Adolescent Time Inventory-Time Attitudes (ATI-TA) to assess time attitudes in Italian adolescents and young adults: Psychometric properties and validity. International Journal of Behavioral Development. (in press.) 
MEASURING TIME ATTITUDES IN YOUNG PEOPLE

Using the Adolescent Time Inventory-Time Attitudes (ATI-TA) to assess time attitudes in Italian adolescents and young adults: Psychometric properties and validity

\begin{abstract}
Time attitudes (TA) are evaluative feelings toward the past, present and future. Given the role of TA in psychological and behavioural outcomes, the aim of this study was to analyze the adequacy of the Adolescent Time Inventory-Time Attitudes (ATI-TA; Mello \& Worrell, 2007) scale among adolescents and young adults in Italy. The scale was administered to 638 students in order to test its psychometric properties and validity. These analyses confirmed the adequacy of the sixfactor model and the reliability of the subscales. Additionally, the measurement invariance of the scale across genders and age groups (between adolescents up to the age of 18, and young adults above 18) was demonstrated. Specifically, gender invariance reached the level of equivalence of error variances/covariances, and the same level was partially reached for invariance across age groups. Evidence of the validity of the scale was also provided by obtaining significant correlations between the subscales, and self-esteem and strategic learning. Taken together, these results support the suitability of the ATI-TA to be used for research and clinical purposes.
\end{abstract}

Keywords: Adolescents; ATI-TA; Dimensionality; Time attitude; Measurement invariance; Validity 


\section{MEASURING TIME ATTITUDES IN YOUNG PEOPLE}

Time perspective (TP) can be described as the subjective and often non-conscious process whereby individuals relate to time, and organize and categorize their personal and social experiences into the temporal frames of the past, present, and future (Boyd \& Zimbardo, 2005). Time perspectives emerge during adolescence, when individuals first develop the ability to consider multiple time dimensions (Piaget, 1955). TPs play an important role in the process of identity formation, which involves the integration of one's personal past, present, and future (Erikson, 1968). Zimbardo and Boyd (1999) have developed a questionnaire, the Zimbardo Time Perspective Inventory (ZTPI), to simultaneously measure five different TPs: past positive and negative, present hedonistic and fatalistic, and future, and they have extensively tested the validity of this questionnaire in young adults.

These investigations have shown that the TPs were related to risk-taking, and both positive and negative psychological outcomes in young adults. Specifically, the present and the future TPs were found to predict - respectively, positively and negatively - risky driving, self-reported alcohol and drug use, unsafe health habits, crime, sexual promiscuity, and addictions (Boyd \& Zimbardo, 2005; Henson, Carey, Carey, \& Maisto, 2006; Keough, Zimbardo \& Boyd, 1999; Wills, Sandy \& Yaeger, 2001; Zimbardo, Keough \& Boyd, 1997). The past negative perspective was also found to correlate negatively with happiness and mindfulness (Drake, Duncan, Sutherland, Abernethy \& Henry, 2008), and the present fatalistic attitude discriminated between severe suicidal ideators and non-ideators (Laghi, Baiocco, D’Alessio \& Gurrieri, 2009), while the future perspective was positively associated with self-efficacy (Luszczynska, Gibbons, Piko \& Tekozel, 2004). Moreover, the time perspective profiles of adolescents in Children's Homes (a population characterised by increased risk-taking tendencies) was also found to differ from adolescents growing up in a family environment (Morsanyi \& Fogarasi, 2014), with characteristic differences in the past and present perspectives. The above studies have demonstrated the ecological validity of the ZTPI in adolescent and college populations. 


\section{MEASURING TIME ATTITUDES IN YOUNG PEOPLE}

Whereas the ZTPI is related to a range of real-life outcomes, there are issues with its psychometric properties (Worrell, Mello, \& Buhl, 2011). One important finding is that the 5-factor structure of the ZTPI was only partially supported in adolescent samples (Worrell \& Mello, 2007). Additionally, at the conceptual level, Worrell et al. (2011) argued that the ZTPI subscales were not pure indicators of time attitudes. For example, present hedonism (e.g., "it is important to put excitement in my life") does not only reflect positive attitudes towards the present, but also a tendency for risk-taking, lack of ego-control and sensation seeking. Similarly, the present fatalistic perspective (e.g., "things rarely work out as I expected") is related to anxiety and depression, in addition to a person's attitudes toward their present. Worrell et al. (2011) also proposed that positive and negative feelings about the future should be considered as separate dimensions, instead of treating them as a single construct.

\section{Time attitudes and the ATI-TA}

According to the multidimensional interpretation (McKay, Cole, Percy, Worrell, \& Mello, 2015; Shipp, Edwards, \& Schurer-Lambert, 2009; Worrell et al., 2011), TP involves various dimensions, including cognitions, feelings, and attitudes towards time. One of these dimensions, Time Attitude (TA), has attracted much research attention. TA refers to "an individual's emotional and evaluative feelings toward the past, the present, and the future" (Worrell, McKay, \& Andretta, 2018, p.1). Similar to TPs, TAs have been found to be related to individuals' everyday functioning, including educational outcomes, psychological wellbeing, and risky behaviour among adolescents. For instance, positive attitudes toward the future are positively correlated with psychological wellbeing. Specifically, an optimistic view of the future was found to be positively linked to self-esteem and negatively related to depression and perceived stress (Scheier \& Carver, 1985). Stress-resilient children reported significantly higher expectations regarding the future than did stress-affected children (Wyman et al., 1992), and Worrell and Hale (2001) found that the belief that the future will work out distinguished between high school dropouts and graduates. Finally, positive attitudes 


\section{MEASURING TIME ATTITUDES IN YOUNG PEOPLE}

toward the future are positively related to self-esteem and positive affect, and negatively related to negative affect (Snyder et al., 1996).

The ATI-TA

Given the importance of TA in adolescence and the lack of reliable and valid psychometric instruments to specifically measure the affective dimension of time perspective from a multidimensional perspective among young people, Mello and Worrell (2007) developed the Adolescent Time Inventory - Time Attitudes (ATI-TA' also known as the ATAS - Adolescent Time Attitude Scale - e.g., Worrell et al., 2011), a self-report scale that measures adolescents' attitudes towards the past, present, and future, including both positive and negative valences. Thus, the ATITA assesses six types of TA: Past Positive, Past Negative, Present Positive, Present Negative, Future Positive and Future Negative, in a holistic way (Andretta, Worrell, Mello, Dixson, \& Baik, 2013).

Studies using the ATI-TA have reported relationships between TAs and both risky behaviours and positive psychological outcomes. For instance, Mello and colleagues (2017) found that adolescents who ran away from home reported less positive and more negative attitudes toward time compared to adolescents who did not run away, with the largest differences in attitudes toward the past. Having positive TAs was also associated with responsible attitudes to alcohol consumption and lower reported alcohol use (Wells, Morgan, Worrell, Sumnall, \& McKay, 2018). Additionally, TAs have been found to be related to grade point average, optimism, hope, perceived stress, and self-esteem among adolescents (Andretta, Worrell, \& Mello, 2014; Mello et al., 2016; Worrell \& Mello, 2009). Significant relationships were also found between time attitude profiles and academic achievement and expectations, self-efficacy, self-esteem, and perceived stress, demonstrating that youth with more positive profiles had more desirable characteristics in terms of academic performance and psychological wellbeing (Alansari, Worrell, Rubie-Davies, \& Webber, 2013; Andretta et al., 2013; Andretta et al., 2014; Buhl \& Linder, 2009). Furthermore, positive feelings towards time were longitudinally predictive of well-being and reduced psychosomatic 


\section{MEASURING TIME ATTITUDES IN YOUNG PEOPLE}

symptomatology (Konowalczyk, McKay, Wells, \& Cole, 2018), increased academic, social, and emotional self-efficacy (Morgan, Wells, Andretta, \& McKay, 2017; Wells, McKay, Morgan, \& Worrell, 2018), and a decrease in sensation seeking, whereas the opposite was true for negative profiles (Morgan et al., 2017).

\section{The psychometric properties of the ATI-TA}

Although the ATI-TA has been widely employed to assess TA in adolescents, relatively less attention has been paid to its psychometric properties. Concerning the dimensionality of the scale, several studies have confirmed that the best structural solution is a six-factor structure in which each dimension measures a positive or negative attitude towards the three time periods (e.g., Alansari et al., 2013; Çelik, Sahranç, Kaya, \& Turan, 2017; Chishima, Murakami, Worrell, \& Mello, 2017; McKay et al., 2015; Mello et al., 2016; Şahin-Baltac1, Tagay, Worrell, \& Mello, 2017; Wells, McKay et al., 2018; Worrell et al., 2013; Worrell et al., 2018). This structure has shown a parsimonious and best solution compared with a two-factor model focussing on valence (i.e., positive and negative) alone (e.g., Alansari et al., 2013; McKay et al., 2015; Mello et al., 2016; Şahin-Baltac1 et al., 2017), and a three-factor model that represents the three time periods (i.e., past, present, and future; e.g., Alansari et al., 2013; McKay et al., 2015; Mello et al., 2016; Şahin-Baltac1 et al., 2017; Worrell et al., 2013; Worrell et al., 2017). Additionally, the six-factor structure has been confirmed in several countries, including Germany (Worrell et al., 2013), Japan (Chishima et al., 2017), and Turkey (Çelik et al., 2017; Şahin-Baltacı et al., 2017).

When analysing the psychometric properties of an instrument, it is important to establish its measurement invariance, which corresponds to the ability of a test to measure a specific construct in the same way across different groups of respondents. This is a central property of a test, as if an instrument does not measure a construct in the same way in different groups of respondents, the comparison of test scores between different groups of individuals has to be considered invalid (Waiyavutti, Johnson, \& Deary, 2011). With regard to the ATI-TA, its invariance across genders, age, time points, and languages has been demonstrated (Mello et al., 2016; Wells, McKay et al., 


\section{MEASURING TIME ATTITUDES IN YOUNG PEOPLE}

2018; Worrell et al., 2013; Worrell et al., 2017). Specifically, Worrell and colleagues (2017) found equivalence of the items' factor loadings and the intercepts of the items regressed on the latent variables across boys and girls in two samples of UK adolescents at three different time points (i.e., when the participants were 12-13 years old, and 12 and 24 months later). Concerning age invariance, Mello et al. (2016) investigated if the ATI-TA could be employed from late adolescence through adulthood to older age by comparing participants from three age groups: between 18-24, 25-59 and 60-85 years. Multigroup confirmatory factor analyses revealed that the scale was invariant across the three age groups at the configural level. With regard to longitudinal invariance across time points of administrations, strict invariance was supported by Wells, McKay et al. (2018), confirming the equivalence of the six-factor structure of the ATI-TA across time points, with a time difference of 24 months. Another study analysed separately the invariance of the positive and negative subscales, finding that the subscales could be considered equivalent only at the configural level, whereas the negative subscales also showed metric invariance (Worrell et al., 2017). Finally, Worrell et al. (2013) tested the cross-cultural invariance of the ATI-TA across American and German samples of adolescents (between 12-20 years of age), demonstrating the scalar invariance of the six-factor model.

Regarding reliability, most of the ATI-TA subscales have been found to show adequate reliability when the internal consistency of the raw scores was assessed by Cronbach's alpha $(\alpha)$ coefficients (Cronbach \& Shavelson, 2004) as well as McDonald's (1999) omega $(\Omega)$, which corresponds to the ratio of true-score variance and the total variance, and, for each factor, it is calculated using the item's coefficients on the factor. Cronbach's alpha coefficients have been found to range from .67 to .89 for the Past Positive subscale, from .72 to .90 for the Past Negative subscale, from .77 to .94 for the Present Positive subscale, from .72 to .91 for the Present Negative subscale, and from .77 to .93 for the Future Positive subscale). The Future Negative subscale appeared to be the weakest, ranging from .53 to .89 (Alansari et al., 2013; Andretta et al., 2013; Çelik et al., 2017; Chishima et al., 2017; McKay et al., 2015; Mello et al., 2016; Prow, Worrell, 


\section{MEASURING TIME ATTITUDES IN YOUNG PEOPLE}

Andretta, \& Mello, 2016; Şahin-Baltacı et al., 2017; Worrell et al., 2013; Worrell et al., 2017). Considering McDonald's (1999) omega $(\Omega)$, a similar pattern of results has been obtained, with values equal to or above .80 for the ATI-TA subscales with a positive valence (Alansari et al., 2013; Chishima et al., 2017; McKay et al., 2015; Mello et al., 2016; Worrell et al., 2017), whereas somewhat lower values have been reported for the Past Negative $(\Omega=.75)$, Present Negative ( $\Omega=.77$ ) (Şahin-Baltacı et al., 2017), and the Future Negative subscale, for which $\Omega$ values ranged from .68 to .78 (McKay et al., 2015; Mello et al., 2016; Worrell et al., 2017), and for the Future Positive subscale, which Mello and colleagues (2016) found to be equal to .74 in the younger and .72 in the older adult sample.

Concerning the validity of the ATI-TA, the majority of the psychometric studies have focused on its structural validity (e.g., Çelik et al., 2017; Mello et al., 2016; Worrell et al., 2013; Worrell et al., 2017), with relatively less attention paid to its criterion validity. These investigations have mostly focussed on the relationships between the six TA subscales and some constructs related to psychological and academic outcomes. For instance, Alansari et al. (2013) found that the six time attitudes had meaningful relationships with attitudes to school, and Şahin-Baltac1 et al., (2017) showed significant correlations between positive attitudes towards the past, present, and future, and negative attitudes towards the present and self-esteem, well-being, and optimism. The relationship with self-esteem was also supported by Chishima et al. (2017), who found significant, moderate correlations among all the positive and negative time attitudes and self-esteem. Worrell and Mello (2009) reported that each of the six time attitudes were significantly and moderately correlated with hope, optimism, self-esteem, and perceived stress. Moreover, McKay et al. (2015) found that academic, social, and emotional self-efficacy were positively related to positive attitudes towards each time period, and negatively related to negative attitudes towards the past, present and future.

Other studies have analysed the validity of time attitude profiles. For instance, Andretta et al. (2014) found that adolescents with a profile of higher positive than negative attitudes reported more favourable educational (grade point average) and psychological (perceived stress and self-esteem) 


\section{MEASURING TIME ATTITUDES IN YOUNG PEOPLE}

outcomes than did adolescents with higher negative attitudes, and Alansari et al. (2013) reported that youth with positive profiles had not only higher academic self-ranking scores and school marks than did adolescents with negative profiles, but they also had more positive attitudes towards both their schools and their teachers.

\section{The current study}

Following these results, the aim of the present study was to investigate the psychometric properties of the ATI-TA among Italian adolescents and young adults. Indeed, to the best of our knowledge, although several studies have analysed the psychometric properties of the ATI-TA in

various languages (e.g., Çelik et al., 2017; Chishima et al., 2017; Şahin-Baltac1 et al., 2017; Worrell et al., 2013), there is a lack of studies on the Italian version of the ATI-TA (Mello, Worrell, Laghi, Baiocco, \& Lonigro, 2011). To fill this gap, we aimed to analyze the adequacy of this instrument in measuring time attitude in adolescents and young adults by confirming its characteristics in terms of dimensionality, invariance, reliability, and validity. Specifically, we aimed to confirm the six-factor model (e.g., Alansari et al., 2013; Çelik et al., 2017; Chishima et al., 2017; McKay et al., 2015; Mello et al., 2016; Şahin-Baltac1 et al., 2017; Wells, McKay et al., 2018; Worrell et al., 2013; Worrell et al., 2017), and to show that this is the best structural solution as compared to the other dimensional solutions tested in literature, i.e., a two-factor model focused on valence (positive and negative) (e.g., Alansari et al., 2013; McKay et al., 2015; Mello et al., 2016; Şahin-Baltac1 et al., 2017), and a three-factor model focussing on time periods (i.e., past, present, and future -e.g., Alansari et al., 2013; McKay et al., 2015; Mello et al., 2016; Şahin-Baltacı et al., 2017; Worrell et al., 2013; Worrell et al., 2017).

We also aimed to test the invariance of the six-factor model across genders and ages, and to compare the time attitudes of males and females, as well as adolescents and young adults. Previous studies using the ATI-TA reported mixed results about gender differences in time attitudes. Specifically, one study found a small in size difference in the Future Negative attitude, with boys scoring higher than girls (Mello \& Worrell, 2006), whereas other studies did not find a gender 


\section{MEASURING TIME ATTITUDES IN YOUNG PEOPLE}

difference in the attitudes toward the past, present, and future (Andretta et al., 2013; Andretta et al., 2014). Concerning age, no significant correlations between age and ATI-TA scores were found

(Andretta et al., 2014; Worrell \& Mello, 2009). Nevertheless, it has been suggested that adolescents are more focused on the future relative to the past and present than adults (Mello, Finan, \& Worrell, 2013).

In order to conduct meaningful multigroup comparisons, it is necessary to demonstrate that the measurement instrument is operating exactly the same way in the compared groups (Byrne, 2004; Dimitrov, 2010; Vandenberg \& Lance, 2000). As we described above, there is evidence for the scalar invariance of the ATI-TA across genders among adolescents between the ages of 12-16 (Worrell et al., 2017). However, the total scale has been found to be invariant across the age groups of late adolescents, young- to middle- aged adults and older adults only at the configural level, as higher levels of invariance were only demonstrated when the six subscales were considered separately. Metric invariance was reached in the case of the Future Positive subscale and scalar invariance was shown for the Present Negative subscale. Nonetheless, on the basis of these results, Mello et al. (2016) concluded that the ATI could be adequately used in both adolescent and adult samples. In order to offer more robust evidence regarding the equivalence of the dimensional structure of the ATI-TA across genders and between adolescence (up to the age of 18) and young adulthood (individuals above 18 years of age), we conducted gender and age invariance analyses.

Concerning the internal consistency of the ATI-TA, we expected to confirm previous results by obtaining high Cronbach's $\alpha$ coefficients (e.g. Alansari et al., 2013; Andretta et al., 2013; Çelik et al., 2017; Chishima et al., 2017; McKay et al., 2015; Mello et al., 2016; Prow et al., 2016; ŞahinBaltac1 et al., 2017; Worrell et al., 2013; Worrell et al., 2017) and McDonald's $\Omega$ values (e.g., Alansari et al., 2013; Chishima et al., 2017; McKay et al., 2015; Mello et al., 2016; Şahin-Baltac1 et al., 2017; Worrell et al., 2017). Indeed, previous findings showed lower internal consistency only in the case of the Future Negative subscale (e.g., McKay et al., 2015; Mello et al., 2016; Worrell et al., 2017). 


\section{MEASURING TIME ATTITUDES IN YOUNG PEOPLE}

Additionally, we aimed to provide empirical support for the scale's criterion validity by confirming the relationships between the six time attitudes and self-esteem, consistent with studies showing significant and positive/negative relationships between self-esteem and positive and negative attitudes toward time, respectively (e.g. Alansari et al., 2013; Andretta et al., 2013; Andretta et al., 2014; Buhl \& Linder, 2009; Worrell \& Mello, 2009). Moreover, given that positive attitudes toward the past and the future have been considered to be linked to good scholastic performance, engagement, and self-efficacy (Alansari et al., 2013; Andretta et al., 2013; Andretta et al., 2014; Buhl \& Linder, 2009; McKay et al., 2015; Morgan et al., 2017; Wells, McKay et al., 2018; Worrell \& Hale, 2001), we aimed to verify that positive time attitudes were related to effective learning. In particular, we aimed to show an association with strategic learning, which entails self-regulatory capacities in controlling commitment, metacognition, satiation, emotion, and environment in order to maximize learning (Dörnyei, 2009).

\section{Methods}

\section{Participants}

The participants were 638 students ( $64 \%$ females) between the ages of 14 and 29 years $(M$ age $=18.3, \mathrm{SD}=2.8)$. The high school sample $\left(n=382,52 \%\right.$ females, $\left.M_{\mathrm{age}}=16.4, \mathrm{SD}=1.5\right)$ was recruited in urban centres of Florence, in Italy. A detailed study protocol which explained the study's goal and methodology was approved by the institutional review board of each school. The students received an information sheet, which assured them that the data obtained would be handled confidentially and anonymously, and they were asked to give written informed assent. Parents of minors were required to provide consent on behalf of their children. All parents gave their permission. The college sample $(\mathrm{n}=256,81 \%$ females, $M \mathrm{age}=21.2, \mathrm{SD}=1.52)$ was recruited from the School of Psychology at the University of Florence, Italy. All participants were first and second year bachelor students, and were recruited using opportunity sampling from various lectures and seminars. All students participated on a voluntary basis, after giving their informed consent.

\section{Materials}




\section{MEASURING TIME ATTITUDES IN YOUNG PEOPLE}

The Adolescent Time Inventory-Time Attitudes (ATI-TA; Mello \& Worrell, 2007; Italian version: Mello et al., 2011) consists of 30 items, related to six dimensions which are evaluated on a 5-point Likert scale ranging from 1 (Totally disagree) to 5 (Totally agree): Past Negative (PaNeg) (5 items; e.g., "My past is a time in my life that I would like to forget"), Past Positive (PaPos) (5 items; e.g., "I have very happy memories of my childhood"), Present Negative (PrNeg) (5 items; e.g., "I am not satisfied with my life right now"), Present Positive (PrPos) (5 items; e.g., "I am happy with my current life"), Future Negative (FuNeg) (5 items; e.g., "I doubt I will make something of myself"), and Future Positive (FuPos) (5 items; "My future makes me happy"). For each subscale, the score is computed by summing the response items and dividing the sum by the number of items for each subscale (e.g., McKay et al., 2015).

To assess self-esteem, we administered the Rosenberg Self-Esteem Scale (RSE; Rosenberg, 1965; Italian Version: Prezza, Trombaccia, \& Armento, 1997), which consists of 10 items, with a 4point Likert scale ranging from 1=strongly agree to $4=$ strongly disagree. An example item is "I feel that I have a number of good qualities". Coefficient alpha for the current sample was good $(\alpha=$ $.81)$.

In order to investigate strategic learning, we administered the Strategic subscale of the Approaches and Study Skills Inventory for Students (ASSIST; Tait, Entwistle, \& McCune, 1998; Italian Version: Chiesi et al., 2015). High scores on the scale indicate learning which is characterized by strong achievement motivation, and is tailored to assessment demands through well-organized and conscientious study methods (including time management), with the aim to perform well (Struyven, Dochy, Janssens, \& Gielen, 2006). An example item is: "I manage to find conditions for studying which allow me to get on with my work easily"). The subscale consists of 8 items rated on a 5-point Likert scale ranging from 1= Disagree to 5=Agree . Coefficient alpha for the current sample was high $(\alpha=.87)$.

\section{Procedure}




\section{MEASURING TIME ATTITUDES IN YOUNG PEOPLE}

The scales were administered individually during class time. All participants completed the ATI-TA. Additionally, in order to analyze the criterion validity, a subsample of the high school group ( $n=216)$ also completed the RSE, whereas a subsample of the college group $(n=88)$ also completed the ASSIST- Strategic subscale, after completing the ATI-TA. The students were provided with a brief introduction to the study, and with some instructions. Answers were collected in a paper-and-pencil format, and data collection was completed in about 20-30 minutes.

\section{Results}

\section{Dimensionality}

Univariate distributions of the ATI-TA items were examined to assess normality. Skewness and Kurtosis indices were between -1 and +1 , except for in the case of three items, which were slightly outside the range of normality (Table 1). However, deviation of a few items from normality can be considered negligible (Ghasemi \& Zahediasl, 2012).

\section{- INSERT TABLE 1 -}

Thus, confirmatory factor analyses were carried out, employing the Maximum Likelihood (ML) method using AMOS (Arbuckle \& Wothke, 1999). The two-factor model, the three-factor model, and the six-factor model were tested. To verify the models' fit, the following indices were taken into account: the ratio of chi-square to its degrees of freedom $\left(\chi^{2} / d f\right)$, the Comparative Fit Index (CFI; Bentler, 1990), the Tucker-Lewis Index (TLI; Tuker \& Lewis, 1973), and the Root Mean Square Error of Approximation (RMSEA; Steiger \& Lind, 1980). Furthermore, we used the Akaike Information Criterion (AIC; Akaike, 1974) and the Bayesian Information Criterion (BIC; Schwarz, 1978) to compare the different models and to choose the model that demonstrated the lowest level of loss of information. In the case of $\chi^{2} / d f$, values below or equal to two are interpreted as good, while values between two and three are interpreted as acceptable (Schermelleh-Engel, Mossbrugger, \& Müller, 2003). For the TLI and CFI indices, values above .90 are indicative of acceptable fit, while values above .95 are indicative of excellent fit (Hu \& Bentler, 1999). The RMSEA value is considered acceptable when it is below .08 and good when it is below .05 (Kline, 


\section{MEASURING TIME ATTITUDES IN YOUNG PEOPLE}

2010). Concerning the AIC and BIC indices, the model that minimizes those indices can be selected as the best model (see Vrieze, 2012, for a discussion about AIC and BIC indices). Table 2 summarizes the goodness-of-fit results for the three tested models.

\section{- INSERT TABLE 2 -}

The results showed that the fit indices of the two-factor model were not acceptable. When we tested the fit of the three-factor model, the results showed a poor overall fit. Modification Indices (MIs) suggested adding error covariance between items 3 and 9, both items belonging to the Past dimension, and between items 7 and 13, both relating to the Future dimension. Scrutiny of the content of each of these items revealed a substantial overlap between item 3 "I have very happy memories of my childhood" and item 9 "I have good memories about growing up", and among item 7 "My future makes me happy" and item 13 "My future makes me smile". This overlap in item content can lead to error covariances (Byrne, 2004). The modified model showed a good fit except for $\chi^{2} / d f$, which was higher than three.

Concerning the six-factor model, the results showed a poor overall fit, but MIs suggested adding error covariance between items 3 and 9, and between the items 7 and 13. Following these modifications, all the fit indices showed acceptable $\left(\chi^{2} / d f\right.$, TLI, RMSEA) or good (CFI) values. Thus, the six-factor model displayed the best fit indices in comparison to the other tested models. Consistent with these analyses, the six-factor model had lower values for the Information Criterion indices (AIC and BIC) than the other models.

Standardized factor loadings ranged from .51 to .88 , and were significant at the .001 level, (effect sizes ranged from .26 to .77). The correlations between the six factors were all significant. Specifically, the correlations between the dimensions referring to the same time period but with opposite valence were very high, ranging from -.82 to -.96 (Figure 1 ).

\section{- INSERT FIGURE 1 -}

\section{Gender Invariance}




\section{MEASURING TIME ATTITUDES IN YOUNG PEOPLE}

Gender invariance analyses were conducted using data from 633 adolescents (Male=229; Female $=404$ ), as five participants did not report their gender. As a prerequisite, we tested the final six-factor model separately in males and females (Byrne, 2004), using AMOS (Arbuckle \& Wothke, 1999). The model showed acceptable fit indices among boys $\left(\chi^{2} / d f=1.76 ; \mathrm{CFI}=.93\right.$; TLI=.92; RMSEA=.058, 90\% CI [.050-.065]), with standardized factor loadings significant at the .001 level and ranging from .43 to .87 (effect sizes ranged from .18 to .76 ). For girls, the model reached acceptable or good fit indices $\left(\chi^{2} / d f=2.05\right.$; CFI $=.95$; TLI $=.95 ; \mathrm{RMSEA}=.051,90 \% \mathrm{CI}$ [.046-.056]). Standardized factor loadings ranged from .47 to .90 and were all significant at the .001 level (effect sizes ranged from .22 to .76).

Analyses were conducted by performing hierarchically nested confirmatory factor analyses (see Byrne, 2004, for testing multigroup invariance with AMOS), and gender invariance was evaluated using not only $\Delta \chi^{2}$, which is sensitive to sample size, but also $\Delta \mathrm{CFI}$, which has been found to be the most sensitive index to detect a lack of invariance (Meade, Johnson, \& Braddy, 2008), employing the absolute value of $\Delta$ CFI of less than .01 (Cheung \& Rensvold, 2002; Dimitrov, 2010).

In line with the recommended practice for testing measurement invariance (Dimitrov, 2010; Little, 1997; Vandenberg \& Lance, 2000), first the independence model was fitted $\left(\chi^{2}=13369.82\right.$, $d f=870, p<.001)$. As reported in Table 3 , in addition to configural invariance $\left(\chi^{2} / d f=2.07, p<.001\right.$, $\mathrm{CFI}=.934, \mathrm{RMSEA}=.041)$, weak or metric factorial invariance was supported $\left(\Delta \chi^{2}=22.53, p=.547\right.$, $\Delta \mathrm{CFI}=.000)$, confirming that the factor loadings were equal across genders. Then, scalar or strict invariance, which constrained intercepts to be invariant across groups, and, subsequently, the equivalence of structural variances and covariances, were also tested $\left(\Delta \chi^{2}\right.$ Model $2-$ Model $3=38.92$, $p=.128, \Delta \mathrm{CFI}=.001 ; \Delta \chi^{2}$ Model 3 - Model $\left.4=21.04, p=.456, \Delta \mathrm{CFI}=.000\right)$. Finally, although we obtained a significant $\Delta \chi^{2}(p<.001)$, the test of the equality of the items' variances and covariances met the $\triangle \mathrm{CFI}$ criterion, as the CFI of the more restrictive model did not decrease by more than .01 . 


\section{MEASURING TIME ATTITUDES IN YOUNG PEOPLE}

\section{Age Invariance}

Age invariance of the ATI-TA was tested by comparing younger adolescents (i.e., adolescents between the ages of 13 and $18 ; 50 \%, \mathrm{n}=318$ ) with older adolescents and young adults (i.e., participants over $18 ; 50 \%, \mathrm{n}=320$ ). First, the final six-factor model was tested separately in the two groups, and the model showed acceptable fit indices among younger adolescents $\left(\chi^{2} / d f=1.90\right.$; CFI=.94; TLI=.94; RMSEA=.053, 90\% CI [.047-.059]), with standardized factor loadings significant at the .001 level and ranging from .48 to .88 (effect sizes ranged from .23 to .77 ). A good fit was also obtained for young adults $\left(\chi^{2} / d f=1.86 ; \mathrm{CFI}=.95 ; \mathrm{TLI}=.94 ; \mathrm{RMSEA}=.052,90 \% \mathrm{CI}\right.$ [.046-.058]). The standardized factor loadings ranged from .41 to .89 and were all significant at the .001 level (effect sizes ranged from .17 to .79).

Preliminarily, the independence model was fitted $\left(\chi^{2}=13454.73, d f=870, p<.001\right)$. Then, after configural invariance was established $\left(\chi^{2} / d f=1.88, p<.001, \mathrm{CFI}=.946, \mathrm{RMSEA}=.037\right)$, metric invariance was assessed (Table 4). Although we obtained a significant $\Delta \chi^{2}(p<.001)$, the $\Delta \mathrm{CFI}$ criterion was met (.002). Further levels of equivalence of intercepts and structural variances and covariances were supported by referring to the same criterion (respectively .001 and .009). Nevertheless, the items' variances and covariances were not invariant across groups either for the $\Delta \chi^{2}(p<.001)$ or the $\Delta$ CFI criterion (.012). Then, partial invariance was tested. As all the MIs exceeded 3.84 (the chi-square value with $d f=1$ ) attesting that all the parameters were significant, the error variances were freed one at time (Dimitrov, 2010). First, we freed the item variances of the Past Positive subscale to be different across samples, and the $\Delta$ CFI was.012. The $\Delta$ CFI criterion was met (.009) after having freed all the item variances of the Past Negative subscale, and after having removed item 5 and item 11 of the Present Positive subscale.

\section{- INSERT TABLE 4 -}

\section{Reliability}

Cronbach's alpha was .90 (95\% CI [.89-.91]) for the Past Negative subscale, .90 (95\% CI [.88-.91]) for the Past Positive subscale, .90 (95\% CI [.88-.91]) for the Present Negative subscale, 


\section{MEASURING TIME ATTITUDES IN YOUNG PEOPLE}

.92 (95\% CI [.91-.93]) for the Present Positive subscale, .74 (95\% CI [.71-.77]) for the Future Negative subscale, and .83 (95\% CI [.81-.85]) for the Future Positive subscale. All corrected itemtotal correlations were above .40 . With regard to McDonald's $\Omega$ values, they were equivalent to the Cronbach's alpha values. Following the cut-offs proposed by the European Federation of Psychologists' Association (EFPA; Evers et al., 2013), the internal consistency value was adequate for the Future Negative subscale, good for the Future Positive subscale, and excellent for the other subscales.

\section{Validity}

In order to analyse the criterion validity of the ATI-TA, we investigated its associations with self-esteem and strategic learning (Table 5). Concerning the relationship between the ATI-TA subscales and the RSE total score, investigated in the high school sample, Pearson correlations showed that all the six ATI-TA dimensions were significantly correlated with self-esteem. In detail, the positive time attitude subscales were positively associated with self-esteem, while negative time attitudes showed a negative relationship. The Pearson coefficient values indicated adequate, good or excellent validity following the cut-offs proposed by the EFPA (Evers et al., 2013). Concerning the relationships with strategic learning, significant and negative correlations were obtained between the ATI-TA negative time attitudes. Regarding the relationships between positive time attitudes and strategic learning, significant positive correlations were obtained, showing adequate validity, with the exception of the Past Positive dimension, for which the correlation was lower than .20.

\section{- INSERT TABLE 5 -}

\section{Gender and age differences}

Having preliminarily verified the measurement equivalence of the scale, a $2 \times 2$ (Gender $\times$ Age group) analysis of variance (ANOVA) was conducted on the ATI-TA subscale scores. Concerning the Past Negative subscale, when comparing female students ( $\mathrm{M}=2.40 ; \mathrm{SD}=.99)$ and male students $(\mathrm{M}=2.31 ; \mathrm{SD}=.94)$, the main effect of Gender was not significant $(F(1,629)=.46$, $p=.497)$. Similarly, when comparing adolescents $(\mathrm{M}=2.38 ; \mathrm{SD}=1.02)$ and young adults $(\mathrm{M}=2.35$; 


\section{MEASURING TIME ATTITUDES IN YOUNG PEOPLE}

$\mathrm{SD}=.92)$, the main effect of Age was not significant $(F(1,629)=.26, p=.612)$, while the interaction effect was significant $\left(F(1,629)=12.66, p<.001\right.$, partial $\left.\eta^{2}=.020\right)$. In detail, females $(M=2.54$, $\mathrm{SD}=1.06)$ outscored males $(\mathrm{M}=2.19, \mathrm{SD}=.95)$ among the group of adolescents, and there was the reverse in the group of young adults $\left(\mathrm{M}_{\text {males }}=2.53, \mathrm{SD}=.91, \mathrm{M}_{\text {females }}=2.29, \mathrm{SD}=.92\right)$.

Regarding the Past Positive subscale, when comparing female students ( $\mathrm{M}=3.60 ; \mathrm{SD}=.90)$ and male students $(\mathrm{M}=3.66 ; \mathrm{SD}=.91)$, the main effect of Gender was not significant $(F(1,629)=.11$, $p=.745)$. Similarly, when comparing adolescents $(\mathrm{M}=3.63 ; \mathrm{SD}=.97)$ and young adults $(\mathrm{M}=3.61$; $\mathrm{SD}=.83)$, the main effect of Age was not significant $(F(1,629)=.84, p=.359)$, while the interaction effect was significant $\left(F(1,629)=7.43, p=.007\right.$, partial $\left.\eta^{2}=.012\right)$. In detail, males $(\mathrm{M}=3.76, \mathrm{SD}=.90)$ outscored females $(\mathrm{M}=3.52, \mathrm{SD}=1.03)$ among the group of adolescents, while there was the reverse in the group of young adults $\left(\mathrm{M}_{\text {males }}=3.48, \mathrm{SD}=.91, \mathrm{M}_{\text {females }}=3.66, \mathrm{SD}=.79\right)$.

For the Present Negative subscale, when comparing female students $(\mathrm{M}=2.51 ; \mathrm{SD}=.88)$ and male students $(\mathrm{M}=2.42 ; \mathrm{SD}=.87)$, the main effect of Gender was not significant $(F(1,629)=.1 .60$, $p=.206)$. Similarly, when comparing adolescents $(\mathrm{M}=2.53 ; \mathrm{SD}=.90)$ and young adults $(\mathrm{M}=2.43$; $\mathrm{SD}=.85)$, the main effect of Age was not significant $(F(1,629)=.68, p=.409)$, while the interaction effect was significant $\left(F(1,629)=6.83, p=.011\right.$, partial $\left.\eta^{2}=.011\right)$. In detail, females $(\mathrm{M}=2.66$, $\mathrm{SD}=.93)$ outscored males $(\mathrm{M}=2.37, \mathrm{SD}=.85)$ among the group of adolescents, while there was the reverse in the group of young adults $\left(\mathrm{M}_{\text {males }}=2.53, \mathrm{SD}=.91, \mathrm{M}_{\text {females }}=2.29, \mathrm{SD}=.92\right)$.

Concerning the Present Positive subscale, the main effect of Gender was significant $\left(F(1,629)=5.51, p=.019\right.$, partial $\left.\eta^{2}=.009\right)$, indicating that female students $(\mathrm{M}=3.50 ; \mathrm{SD}=.83)$ outscored male students $(\mathrm{M}=3.26 ; \mathrm{SD}=.75)$. Tthe main effect of Age $(F(1,629)=37.90, p<.001$, partial $\left.\eta^{2}=.057\right)$ was also significant. In detail, adolescents $(\mathrm{M}=3.18 ; \mathrm{SD}=.80)$ scored lower than young adults $(\mathrm{M}=3.64 ; \mathrm{SD}=.75)$. The interaction effect was not significant $(F(1,629)=1.37, p=.240)$.

For the Future Negative subscale, when comparing female students $(\mathrm{M}=2.07 ; \mathrm{SD}=.70)$ and male students $(\mathrm{M}=2.16 ; \mathrm{SD}=.68)$, the main effect of Gender was not significant $(F(1,629)=1.16$, 


\section{MEASURING TIME ATTITUDES IN YOUNG PEOPLE}

$p=.282)$, while the effect of Age was significant $\left(F(1,629)=5.36, p=.021\right.$, partial $\left.\eta^{2}=.008\right)$, indicating that adolescents $(\mathrm{M}=2.18 ; \mathrm{SD}=.76)$ outscored young adults $(\mathrm{M}=2.02 ; \mathrm{SD}=.61)$. The interaction effect was not significant $(F(1,629)=.97, p=.325)$.

Finally, looking at the Future Positive subscale, when comparing female students ( $\mathrm{M}=3.73$; $\mathrm{SD}=.72)$ and male students $(\mathrm{M}=3.30 ; \mathrm{SD}=.67)$, the main effect of Gender was not significant $(F(1,629)=.73, p=.393)$, while the effect of Age was significant $\left(F(1,629)=7.03, p=.008\right.$, partial $\eta^{2}$ $=.011)$. indicating that young adults $(\mathrm{M}=3.45 ; \mathrm{SD}=.67)$ outscored adolescents $(\mathrm{M}=3.24 ; \mathrm{SD}=.71)$. Also the interaction effect was significant $\left(F(1,629)=6.72, p=.010\right.$, partial $\left.\eta^{2}=.011\right)$. In detail, while males $(M=3.30, S D=.67)$ outscored females $(M=3.19, S D=.75)$ among the group of adolescents, there was the reverse in the group of young adults $\left(\mathrm{M}_{\text {males }}=3.30, \mathrm{SD}=.66, \mathrm{M}_{\mathrm{females}}=3.50\right.$, $\mathrm{SD}=.67)$.

\section{Discussion}

In order to provide further evidence that the ATI-TA is an adequate measurement tool to assess time attitudes in young people, the aim of the present study was to investigate the psychometric properties of the scale among Italian adolescents and young adults. Overall, the findings confirmed and extended previous results regarding the scale's psychometric characteristics, in terms of its dimensionality, invariance across genders and ages, reliability, and validity.

Specifically, the confirmatory factor analyses supported the six-factor structure of the scale, in line with previous research (e.g., Alansari et al., 2013; Çelik et al., 2017; Chishima et al., 2017; McKay et al., 2015; Mello et al., 2016; Şahin-Baltac1 et al., 2017; Wells, McKay et al., 2018; Worrell et al., 2013; Worrell et al., 2017). This is a fundamental prerequisite to use the ATI-TA, as this instrument is also used to establish time attitude profiles, which are based on scores on each of the six subscales (e.g., Andretta et al., 2014; Prow et al., 2016; Wells, McKay et al., 2018).

Additionally, this study has found that the six-factor model was invariant across genders, by confirming the equivalence of the configural model, the factor loadings, the intercepts, the factor 


\section{MEASURING TIME ATTITUDES IN YOUNG PEOPLE}

variances and covariances, and the measurement residuals across male and female respondents. As a previous study has shown scalar invariance across genders (Worrell et al., 2017), having reached higher level of equivalence in the multigroup confirmatory analysis represents an important novelty in the psychometric literature focused on the ATI-TA. Moreover, this result is of particular importance, as the issue of gender differences and similarities in adolescent TA has been widely debated in the literature (e.g., Andretta et al., 2013; Andretta et al., 2014; Mello \& Worrell, 2006). Extending Worrell and colleagues' (2017) results obtained with younger participants, we have found that the ATI-TA scores also have "the same meaning" (Reise \& Waller, 2009) across males and females in a young adult sample. Overall, the ATI-TA is an effective and adequate measurement tool to compare attitude towards time between male and female respondents. That is, group differences or similarities can be interpreted as true differences or similarities in the underlying construct.

This study also offers empirical evidence for the invariance of the ATI-TA across adolescents and young adults, reaching the level of equivalence of measurement error variances/covariances. However, this level was only partially supported. Nevertheless, partial invariance should be interpreted as a situation in which there is no perfect invariance for the specific parameters - in this case, error variances - but neither is there evidence of their complete inequality (Dimitrov, 2010). Furthermore, linking this result to previous research, although Mello et al. (2016) suggested that the ATI-TA could be considered a measurement tool suitable for adolescents as well as adults, based on their invariance analyses, they only reached configural invariance for the total scale across three age groups ranging from late adolescence to older age. Our results represent a more robust empirical evidence of the age invariance of the ATI-TA, that allows researchers to use this tool to investigate age differences and similarities in TA by comparing mean scores (e.g., (Andretta et al., 2014; Worrell \& Mello, 2009).

Concerning gender and age differences, we have only found a small in size gender difference in the Present Positive perspective, with girls scoring higher than boys, while for the other scales 


\section{MEASURING TIME ATTITUDES IN YOUNG PEOPLE}

any differences were found (Andretta et al., 2013; Andretta et al., 2014), and a significant age differences in the Past Positive and Future Positive, in which young adults outscored adolescents, and in Future Negative, in which adolescents scored higher than young adolescents. The differences in the Future are consistent with the suggestion that the perception of the future characterizes adolescents (Mello, Finan, \& Worrell, 2013). Our findings are important mostly in the light of the literature suggesting mixed results regarding gender and age differences in TP. Indeed, although females have been found to be more focused on the future and to have a more positive future outlook, and to see the past in a more positive way than males (Keough et al., 1999; Morsanyi \& Fogarasi, 2014; Zimbardo \& Boyd, 1999), and males scored higher than females in the tendency to perceive the present hedonistically (Keough et al., 1999), some other studies did not find significant gender differences (McCabe \& Barnett, 2000). There is a similar inconsistency in findings regarding age differences, with some studies showing an increase in future orientation and a decrease in present- and past orientation during adolescence, whereas other research suggests that adolescents focus more on the present, especially in terms of a hedonistic perception of the present, rather than the past or the future (see Mello \& Worrell, 2006). Having an instrument that can be considered invariant across genders and age represents a great advantage in pursuing this line of research regarding the broader construct of $\mathrm{TP}$.

Concerning reliability, our results are in line with previous studies (e.g. Alansari et al., 2013; Andretta et al., 2013; Çelik et al., 2017; McKay et al., 2015; Mello et al., 2016; Prow et al., 2016; Şahin-Baltac1 et al., 2017; Worrell et al., 2013) in showing that all Cronbach's alpha and McDonald's $\Omega$ values were good or excellent, with the Future Negative subscale characterized by a lower level of internal consistency than the other TAs, even though the alpha values were adequate in our study.

Finally, with respect to validity, evidence of adequate, good, or excellent concurrent validity was obtained considering the relationship between the ATI-TA scores and self-esteem (e.g., Andretta et al. 2014; Şahin-Baltacı et al., 2017; Worrell \& Mello, 2009) and strategic learning, 


\section{MEASURING TIME ATTITUDES IN YOUNG PEOPLE}

confirming the association of time attitudes with school engagement and effective learning strategies (Worrell \& Hale, 2001). The pattern of correlations also suggests that self-esteem is particularly strongly related to the present perspectives, whereas (a lack of) strategic learning was most strongly predicted by negative time attitudes.

Concerning the practical implications, this study suggests that the ATI-TA can be adequately used to measure TA in research and practice involving Italian youth. From a research point of view, as the ATI-TA has been widely employed with adolescents, highlighting that TA is related to various types of risky behaviours, i.e., having positive attitudes towards alcohol and using alcohol (Wells, Morgan, et al., 2018), and both positive and negative psychological outcomes, such as perceived stress and psychosomatic symptomatology, optimism, hope, self-esteem, academic achievement and expectations, as well as self-efficacy (Alansari et al., 2013; Andretta et al., 2013; Andretta et al., 2014; Buhl \& Linder, 2009; Konowalczyk et al., 2018; Mello et al., 2016; Morgan et al., 2017; Wells, McKay, et al., 2018; Worrell \& Mello, 2009), this study offers evidence of the adequacy of using this instrument for research into adolescent behavioral and psychological outcomes. Moreover, as more and more studies are using the ATI-TA to assess time attitude, offering proof of the robustness of the scale from a psychometric point of view allows researchers to draw more reliable and valid interpretations of their findings concerning the psychological functioning of adolescents and young adults.

From a practical perspective, the ATI-TA provides specific and detailed cues for developing ad-hoc interventions. Indeed, the instrument could help practitioners in the early identification of adolescents characterized by negative attitudes toward the different time periods, and in planning educational interventions for them. For instance, if adolescents with negative time attitudes toward the past, present or future are detected, they could be educated at looking at their past or present experiences in searching for the reasons why they have this kind of attitude. Moreover, they could be helped in developing more adaptive views of their future using individual activities that are aimed at converting negative thoughts into positive beliefs about the future. 


\section{MEASURING TIME ATTITUDES IN YOUNG PEOPLE}

Some limitations of this study have to be pointed out, such as an imbalance of genders across the adolescent and young adult samples, and the fact that the overall sample was from a specific geographic area of Italy. As a result, the sample cannot be considered to be nationally representative. Additionally, the older group included college students who can be considered a selective group of high-achieving young adults. Thus, further investigations are needed to strengthen the present findings. For instance, by also including early adolescents, i.e., students attending middle school, it might be interesting to also test the invariance of the scale across school grades, extending research on the measurement invariance of the ATI-TA across age groups (Mello et al., 2016). The psychometric properties of the scale could also be tested among adults without college education. Moreover, the criterion validity of the scale should be more thoroughly investigated.

To conclude, the present results provide evidence that the Italian version of the ATI-TA is psychometrically appropriate to be used with young people in order to assess TA. This is a promising finding as the ATI-TA is the only measure that currently assesses both positive and negative attitudes toward the past, the present, and the future, without confounding this measurement with the assessment of other psychological constructs.

\section{References}

Akaike, H. (1974). A new look at the statistical model identification. IEEE transactions on automatic control, 19(6), 716-723.

Alansari, M., Worrell, F. C., Rubie-Davies, C., \& Webber, M. (2013). Adolescent Time Attitude Scale (ATAS) scores and academic outcomes in secondary school females in New Zealand. International Journal of Quantitative Research in Education, 1, 251-274. https://doi.org/10.1504/IJQRE.2013.057687

Andretta, J. R., Worrell, F. C., \& Mello, Z. R. (2014). Predicting educational outcomes and psychological well-being in adolescents using time attitude profiles. Psychology in the Schools, 51(5), 434-451. DOI: 10.1002/pits.21762 


\section{MEASURING TIME ATTITUDES IN YOUNG PEOPLE}

Andretta, J. R., Worrell, F. C., Mello, Z. R., Dixson, D. D., \& Baik, S. H. (2013). Demographic group differences in adolescents' time attitudes. Journal of Adolescence, 36(2), 289-301. https://doi.org/10.1016/j.adolescence.2012.11.005

Arbuckle, J., \& Wothke, W. (1999). AMOS 4 user's reference guide. Chicago: Smallwaters Corporation.

Bentler, P. M. (1990). Comparative fit indexes in structural models. Psychological Bulletin, 107(2), 238-246.

Boyd, J. N., \& Zimbardo, P. G. (2005). Time perspective, health, and risk taking. In A. Strathman, \& J. Joireman (Eds.), Understanding behavior in the context of time: Theory, research, and application (pp. 85-107). Mahwah, NJ: Lawrence Erlbaum Associates.

Buhl, M., \& Linder, D. (2009). Time perspectives in adolescence: Measurement, profiles, and links with personality characteristics and scholastic experience. Diskurs Kindheits und Jungendforschung, 2, 197-216.

Byrne, B. M. (2004). Testing for multigroup invariance using AMOS graphics: A road less traveled. Structural Equation Modeling, 11(2), 272-300. https://doi.org/10.1207/s15328007sem1102_8

Çelik, E., Sahranç, Ü., Kaya, M., \& Turan, M. E. (2017). Adolescent Time Attitude Scale: Adaptation into Turkish. Universal Journal of Educational Research, 5(2), 249-254. DOI: 10.13189/ujer.2017.050210

Cheung, G. W., \& Rensvold, R. B. (2002). Evaluating goodness-of-fit indexes for testing measurement invariance. Structural Equation Modeling, 9(2), 233-255. https://doi.org/10.1207/S15328007SEM0902_5

Chiesi, F., Primi, C., Bilgin, A. A., Lopez, M. V., del Carmen Fabrizio, M., Gozlu, S., \& Tuan, N. M. (2015). Measuring University Students’ Approaches to Learning Statistics: An Invariance Study. Journal of Psychoeducational Assessment, 1-13. 


\section{MEASURING TIME ATTITUDES IN YOUNG PEOPLE}

Chishima, Y., Murakami, T., Worrell, F. C., \& Mello, Z. R. (2017). The Japanese Version of the Adolescent Time Inventory-Time Attitudes (ATI-TA) Scale: Internal Consistency, Structural Validity, and Convergent Validity. Assessment, https://doi.org/10.1177/1073191116683800

Cronbach, L. J., \& Shavelson, R. J. (2004). My current thoughts on coefficient alpha and successor procedures. Educational and Psychological Measurement, 64(3), 391-418. https://doi.org/10.1177/0013164404266386

Dimitrov, D. M. (2010). Testing for Factorial Invariance in the Context of Construct Validation. Measurement and Evaluation in Counseling and Development, 43(2), 121-149. https://doi.org/10.1177/0748175610373459

Dörnyei, Z. (2009). Individual differences: Interplay of learner characteristics and learning environment. Language Learning, 59(s1), 230-248. DOI: 10.1111/j.1467-9922.2009.00542.x

Drake, L., Duncan, E., Sutherland, F., Abernethy, C., \& Henry, C. (2008). Time perspective and correlates of wellbeing. Time \& Society, 17(1), 47-61. https://doi.org/10.1177/0961463X07086304

Erikson, E. (1968). Identity: Youth and crisis. New York: Norton.

Evers, A., Hagemeister, C., Høstmælingen, A., Lindley, P., Muñiz, J., \& Sjöberg, A. (2013, July). EFPA Review Model for the description and evaluation of psychological and educational tests. Test review form and notes for reviewers. Version 4.2.6.

Ghasemi, A., \& Zahediasl, S. (2012). Normality tests for statistical analysis: a guide for nonstatisticians. International Journal of Endocrinology and Metabolism, 10(2), 486-489. DOI: 10.5812/ijem.3505

Henson, J. M., Carey, M. P., Carey, K. B., \& Maisto, S. A. (2006). Associations among health behaviors and time perspective in young adults: Model testing with boot-strapping replication. Journal of Behavioral Medicine, 29(2), 127-137. https://doi.org/10.1007/s10865-005-9027-2 


\section{MEASURING TIME ATTITUDES IN YOUNG PEOPLE}

Hu, L. T., \& Bentler, P. M. (1999). Cutoff criteria for fit indexes in covariance structure analysis: Conventional criteria versus new alternatives. Structural Equation Modeling: A Multidisciplinary Journal, 6(1), 1-55. https://doi.org/10.1080/10705519909540118

Keough, K. A., Zimbardo, P. G., \& Boyd, J. N. (1999). Who's smoking, drinking, and using drugs? Time perspective as a predictor of substance use. Basic and applied social psychology, 21(2), $149-164$

Kline, R. B. (2010). Principles and Practice of Structural Equation Modeling (3rd ed.). New York: Guilford Press.

Konowalczyk, S., McKay, M. T., Wells, K. E., \& Cole, J. C. (2018). The Influence of Time Attitudes Profile Membership on Mental Well-being and Psychosomatic Symptomatology: A United Kingdom-based Prospective Study. Psychiatry Research, 375-382. https://doi.org/10.1016/j.psychres.2017.12.071

Laghi, F., Baiocco, R., D'Alessio, M., \& Gurrieri, G. (2009). Suicidal ideation and time perspective in high school students. European Psychiatry, 24(1), 41-46.

https://doi.org/10.1016/j.eurpsy.2008.08.006

Little, T. D. (1997). Mean and covariance structures (MACS) analyses of cross-cultural data: Practical and theoretical issues. Multivariate Behavioral Research, 32(1), 53-76. Luszczynska, A., Gibbons, F. X., Piko, B. F., \& Tekozel, M. (2004). Self-regulatory cognitions, social comparison, and perceived peers' behaviors as predictors of nutrition and physical activity: A comparison among adolescents in Hungary, Poland, Turkey, and USA. Psychology \& Health, 19(5), 577-593. https://doi.org/10.1080/0887044042000205844

McCabe, K., \& Barnett, D. (2000). First comes work, then comes marriage: Future orientation among African American young adolescents. Family Relations, 49(1), 63-70.

McDonald, R. P. (1999). Test theory: A unified treatment. Mahwah, NJ. Erlbaum.

McKay, M. T., Cole, J. C., Percy, A., Worrell, F. C., \& Mello, Z. R. (2015). Reliability and factorial validity of Adolescent Time Inventory-Time Attitude (ATI-TA) scores in Scottish and 


\section{MEASURING TIME ATTITUDES IN YOUNG PEOPLE}

Northern Irish adolescents. Personality and Individual Differences, 86, 412-416. https://doi.org/10.1016/j.paid.2015.06.040

Meade, A. W., Johnson, E. C., \& Braddy, P. W. (2008). Power and sensitivity of alternative fit indices in tests of measurement invariance. Journal of Applied Psychology, 93(3), 568-592. DOI: $10.1037 / 0021-9010.93 .3 .568$

Mello, Z. R., Finan, L. J., \& Worrell, F. C. (2013). Introducing an instrument to assess time orientation and time relation in adolescents. Journal of Adolescence, 36(3), 551-563. https://doi.org/10.1016/j.adolescence.2013.03.005

Mello, Z. R., Walker, E. B., Finan, L. J., Stiasny, A., Wiggers, I. C., McBroom, K. A., \& Worrell, F. C. (2017). Time perspective, psychological outcomes, and risky behavior among runaway adolescents. Applied Developmental Science, 1-11. https://doi.org/10.1080/10888691.2016.1276455

Mello, Z. R., \& Worrell, F. C. (2006). The relationship of time perspective to age, gender, and academic achievement among academically talented adolescents. Journal for the Education of the Gifted, 29(3), 271-289. https://doi.org/10.1177/016235320602900302

Mello, Z. R., \& Worrell, F. C. (2007). The Adolescent Time Attitude Scale-English. University of California, Berkeley, CA: Author.

Mello, Z. R., Worrell, F. C., Laghi, F., Baiocco, R., \& Lonigro, A. (2011). The Adolescent time Inventory-Italian. Unpublished scale: The University of Colorado, Colorado Springs and Sapienza University of Rome.

Mello, Z. R., Zhang, J. W., Barber, S. J., Paoloni, V. C., Howell, R. T., \& Worrell, F. C. (2016). Psychometric properties of time attitude scores in young, middle, and older adult samples. Personality and Individual Differences, 101, 57-61. https://doi.org/10.1016/j.paid.2016.05.037

Morgan, G. B., Wells, K. E., Andretta, J. R., \& McKay, M. T. (2017). Temporal attitudes profile transition among adolescents: A longitudinal examination using mover- stayer latent 


\section{MEASURING TIME ATTITUDES IN YOUNG PEOPLE}

transition analysis. Psychological Assessment, 29(7), 890-901.

http://dx.doi.org/10.1037/pas0000383

Morsanyi, K., \& Fogarasi, E. (2014). Thinking about the past, present and future in adolescents growing up in Children's Homes. Journal of Adolescence, 37(7), 1043-1056. https://doi.org/10.1016/j.adolescence.2014.07.011

Piaget, J. (1955). The development of time concepts in the child. In P. H. Hoch \& J. Zubin (Eds.), Psychopathology of childhood (pp. 34-44). London: Grube and Stratton.

Prezza, M., Trombaccia, F.R., \& Armento, L. (1997). La scala dell'autostima di Rosenberg: traduzione e validazione italiana. Bollettino di Psicologia Applicata, 223, 35-44.

Prow, R. M., Worrell, F. C., Andretta, J. R., \& Mello, Z. R. (2016). Demographic Differences in Adolescent Time Attitude Profiles in an Urban High School: A Person-Oriented Analysis Using Model-Based Clustering. Berkeley Review of Education, 6(1), 79-95. https://escholarship.org/uc/item/4bb6r8n6

Reise, S. P., \& Waller, N. G. (2009). Item response theory and clinical measurement. Annual Review of Clinical Psychology, 5, 27-48. https://doi.org/10.1146/annurev.clinpsy.032408.153553

Rosenberg, M. (1965). Rosenberg self-esteem scale (RSE). Acceptance and commitment therapy. Measures package, 61, 52.

Şahin-Baltac1, H., Tagay, Ö., Worrell, F. C., \& Mello, Z. R. (2017). Psychometric properties of Turkish Adolescent Time Inventory-Time Attitude (ATI-TA) scores. International Perspectives in Psychology: Research, Practice, Consultation, 6(1), 47-59. http://dx.doi.org/10.1037/ipp0000066

Scheier, M. F., \& Carver, C. S. (1985). Optimism, coping, and health: assessment and implications of generalized outcome expectancies. Health Psychology, 4(3), 219-247. 


\section{MEASURING TIME ATTITUDES IN YOUNG PEOPLE}

Schermelleh-Engel, K., Moosbrugger, H., \& Müller, H. (2003). Evaluating the fit of structural equation models: Tests of significance and descriptive goodness-of-fit measures. Methods of Psychological Research Online, 8(2), 23-74. http://www.mpr-online.de

Schwarz, G. (1978). Estimating the dimension of a model. The Annals of Statistics, 6(2), 461-464.

Shipp, A. J., Edwards, J. R., \& Lambert, L. S. (2009). Conceptualization and measurement of temporal focus: The subjective experience of the past, present, and future. Organizational Behavior and Human Decision Processes, 110(1), 1-22. DOI: 10.1016/j.obhdp.2009.05.001

Snyder, C. R., Sympson, S. C., Ybasco, F. C., Borders, T. F., Babyak, M. A., \& Higgins, R. L. (1996). The development and validation of the Stage Hope Scale. Journal of Personality and Social Psychology, 2, 321 - 335Steiger, J. H., \& Lind, J. C. (1980, April). Statistically-based tests for the number of common factors. Annual spring meeting of the Psychometric Society, Iowa City.

Steiger, J. H., \& Lind, J. C. (1980, May). Statistically based tests for the number of common factors. In annual meeting of the Psychometric Society, Iowa City, IA (Vol. 758, pp. 424-453).

Struyven, K., Dochy, F., Janssens, S., \& Gielen, S. (2006). On the dynamics of students' approaches to learning: The effects of the teaching/learning environment. Learning and Instruction, 16(4), 279-294. https://doi.org/10.1016/j.learninstruc.2006.07.001

Tait, H., Entwistle, N. J., \& McCune, V. (1998). ASSIST: A reconceptualisation of the approaches to studying inventory. Improving student learning: Improving students as learners, 262-271.

Tucker, L. R., \& Lewis, C. (1973). A reliability coefficient for maximum likelihood factor analysis. Psychometrika, 38, 1-10.

Vandenberg, R. J., \& Lance, C. E. (2000). A review and synthesis of the measurement invariance literature: Suggestions, practices, and recommendations for organizational research. Organizational Research Methods, 3(1), 4-70.

https://doi.org/10.1177/109442810031002 


\section{MEASURING TIME ATTITUDES IN YOUNG PEOPLE}

Vrieze, S. I. (2012). Model selection and psychological theory: A discussion of the differences between the Akaike Information Criterion (AIC) and the Bayesian Information Criterion (BIC). Psychological Methods, 17(2), 228-243. DOI: 10.1037/a0027127

Waiyavutti, C., Johnson, W., and Deary, I. J. (2011). Do personality scale items function differently in people with high and low IQ? Psychological Assessment, 24, 545-555. DOI: $10.1037 / \mathrm{a} 0026266$

Wells, K. E., Morgan, G., Worrell, F. C., Sumnall, H., \& McKay, M. T. (2018). The influence of time attitudes on alcohol-related attitudes, behaviors and subjective life expectancy in early adolescence: A longitudinal examination using mover-stayer latent transition analysis. International Journal of Behavioral Development, 42(1), 93-105. https://doi.org/10.1177/0165025416679740

Wells, K. E., McKay, M. T., Morgan, G. B., \& Worrell, F. C. (2018). Time attitudes predict changes in adolescent self-efficacy: A 24-month latent transition mover-stayer analysis. Journal of Adolescence, 62, 27-37. https://doi.org/10.1016/j.adolescence.2017.10.005

Wills, T. A., Sandy, J. M., \& Yaeger, A. M. (2001). Time perspective and early-onset substance use: A model based on stress-coping theory. Psychology of Addictive Behaviors, 15(2), 118125. http://dx.doi.org/10.1037/0893-164X.15.2.118

Worrell, F. C., \& Hale, R. L. (2001). The relationship of hope in the future and perceived school climate to school completion. School Psychology Quarterly, 16(4), 370-388. http://dx.doi.org/10.1521/scpq.16.4.370.19896

Worrell, F. C., \& Mello, Z. R. (2007). The reliability and validity of Zimbardo Time Perspective Inventory scores in academically talented adolescents. Educational and Psychological Measurement, 67(3), 487-504. https://doi.org/10.1177/0013164406296985

Worrell, F. C., \& Mello, Z. R. (2009). Convergent and discriminant validity of time attitude scores on the Adolescent Time Perspective Inventory. Diskurs Kindheits und Jugendforschung [Research on Child and Adolescent Development], 4, 185-196- 


\section{MEASURING TIME ATTITUDES IN YOUNG PEOPLE}

Worrell, F. C., Mckay, M. T., \& Andretta, J. R. (2018). Psychometric properties of Adolescent Time Inventory Time Attitude (ATI-TA) scores in three waves of longitudinal data. Psychological Assessment, 30(1), 106-115. DOI: 10.1037/pas0000457

Worrell, F. C., Mello, Z. R., \& Buhl, M. (2013). Introducing English and German versions of the adolescent time attitude scale. Assessment, 20(4), 496-510. https://doi.org/10.1177/1073191110396202

Wyman, P. A., Cowen, E. L., Work, W. C., Raoof, A., Gribble, P. A., Parker, G. R., \& Wannon, M. (1992). Interviews with children who experienced major life stress: Family and child attributes that predict resilient outcomes. Journal of the American Academy of Child \& Adolescent Psychiatry, 31(5), 904-910.

Zimbardo, P. G. \& Boyd, J. N. (1999). Putting time in perspective: A valid, reliable individualdifferences metric. Journal of Personality and Social Psychology, 77, 1271-1288.

Zimbardo, P. G., Keough, K. A., \& Boyd, J. N. (1997). Present time perspective as a predictor of risky driving. Personality and Individual Differences, 23(6), 1007-1023. 
Table 1

Means, standard deviations, skewness, and kurtosis of the thirty items of the Adolescent Time Inventory-Time Attitudes (ATI-TA)

\begin{tabular}{|c|c|c|c|c|}
\hline Item & $\mathrm{M}$ & SD & Skewness & Kurtosis \\
\hline 1 & 3.48 & .90 & -.45 & .19 \\
\hline 2 & 2.56 & 1.08 & .32 & -.65 \\
\hline 3 & 3.88 & 1.07 & -.95 & .31 \\
\hline 4 & 1.77 & 0.87 & 1.04 & .70 \\
\hline 5 & 3.59 & .93 & -.58 & .08 \\
\hline 6 & 2.07 & 1.11 & .93 & .22 \\
\hline 7 & 3.33 & .86 & -.16 & .19 \\
\hline 8 & 2.56 & 1.05 & .41 & -.53 \\
\hline 9 & 3.96 & 1.01 & -1.11 & .99 \\
\hline 10 & 1.98 & .93 & .89 & .49 \\
\hline 11 & 3.52 & .90 & -.58 & .07 \\
\hline 12 & 2.53 & 1.14 & .50 & -.60 \\
\hline 13 & 3.12 & .94 & -.15 & -.07 \\
\hline 14 & 3.52 & .93 & -.61 & .12 \\
\hline 15 & 2.44 & 1.13 & .48 & -.62 \\
\hline 16 & 2.26 & 1.01 & .57 & -.20 \\
\hline 17 & 3.66 & .91 & -.78 & .49 \\
\hline 18 & 2.22 & 1.19 & .76 & -.32 \\
\hline 19 & 3.44 & .93 & -.28 & .10 \\
\hline 20 & 2.43 & 1.03 & .52 & -.32 \\
\hline 21 & 3.60 & 1.03 & -.77 & .13 \\
\hline 22 & 2.37 & 1.07 & .58 & -.22 \\
\hline 23 & 2.28 & 1.05 & .62 & -.23 \\
\hline 24 & 3.26 & 1.12 & -.36 & -.58 \\
\hline 25 & 2.14 & 1.07 & .75 & -.05 \\
\hline 26 & 3.69 & .87 & -.79 & .76 \\
\hline 27 & 2.58 & 1.20 & .27 & -1.05 \\
\hline 28 & 3.34 & .95 & -.17 & -.16 \\
\hline 29 & 2.57 & 1.05 & .35 & -.64 \\
\hline 30 & 3.43 & 1.13 & -.47 & -.52 \\
\hline
\end{tabular}

Note. The Adolescent Time Inventory-Time Attitudes (ATI-TA) Likert scale is the following: $1=$ "Totally Disagree", 2 = "Disagree", 3 = "Neutral", $4=$ "Agree", $5=$ "Totally Agree". $n=638$ 
Table 2

Goodness-of-fit statistics for the two-factor, the three-factor, and the six-factor models of the Adolescent Time Inventory-Time Attitudes (ATI-TA)

\begin{tabular}{|c|c|c|c|c|c|c|c|c|}
\hline Models & $\chi^{2}$ & $d f$ & $\chi^{2} / d f$ & TLI & CFI & $\begin{array}{l}\text { RMSEA } \\
{[90 \% \mathrm{CI}]}\end{array}$ & AIC & $\mathrm{BIC}$ \\
\hline Two-factor model & 3486.45 & 404 & 16.06 & .473 & .511 & $\begin{array}{c}.154 \\
{[.150-.157]}\end{array}$ & 6608.45 & 6880.41 \\
\hline Three-factor model & 1620.82 & 400 & 4.03 & .894 & .902 & $\begin{array}{c}.069 \\
{[.065-.073]}\end{array}$ & 1746.82 & 2027.70 \\
\hline $\begin{array}{c}\text { Modified Three- } \\
\text { factor model* }\end{array}$ & 1415.86 & 400 & 3.54 & .911 & .918 & $\begin{array}{c}.063 \\
{[.060-.067]}\end{array}$ & 1545.86 & 1835.66 \\
\hline Six-factor model & 1243.09 & 390 & 3.19 & .923 & .931 & $\begin{array}{c}.059 \\
{[.055-.062]}\end{array}$ & 1393.09 & 1727.46 \\
\hline $\begin{array}{c}\text { Modified Six-factor } \\
\text { model }^{* *}\end{array}$ & 965.21 & 388 & 2.49 & .948 & .954 & $\begin{array}{c}.048 \\
{[.045-.052]}\end{array}$ & 1119.21 & 1462.50 \\
\hline
\end{tabular}

Note. * Three-factor model with error covariances between items 3 and 9, and between items 7 and 13, added. ** Six-factor model with error covariances between items 3 and 9, and between items 7 and 13, added. $\chi^{2}=$ chi square test; $d f=$ degrees of freedom; CFI = comparative fit index; RMSEA $=$ robust root mean square error of approximation; $90 \% \mathrm{CI}=90 \%$ Confidence Interval; AIC $=$ Akaike Information Criterion; BIC $=$ Bayesian Information Criterion. $n=638$ 
Table 3

Goodness-of-fit statistics for each level of structural and measurement invariance across genders

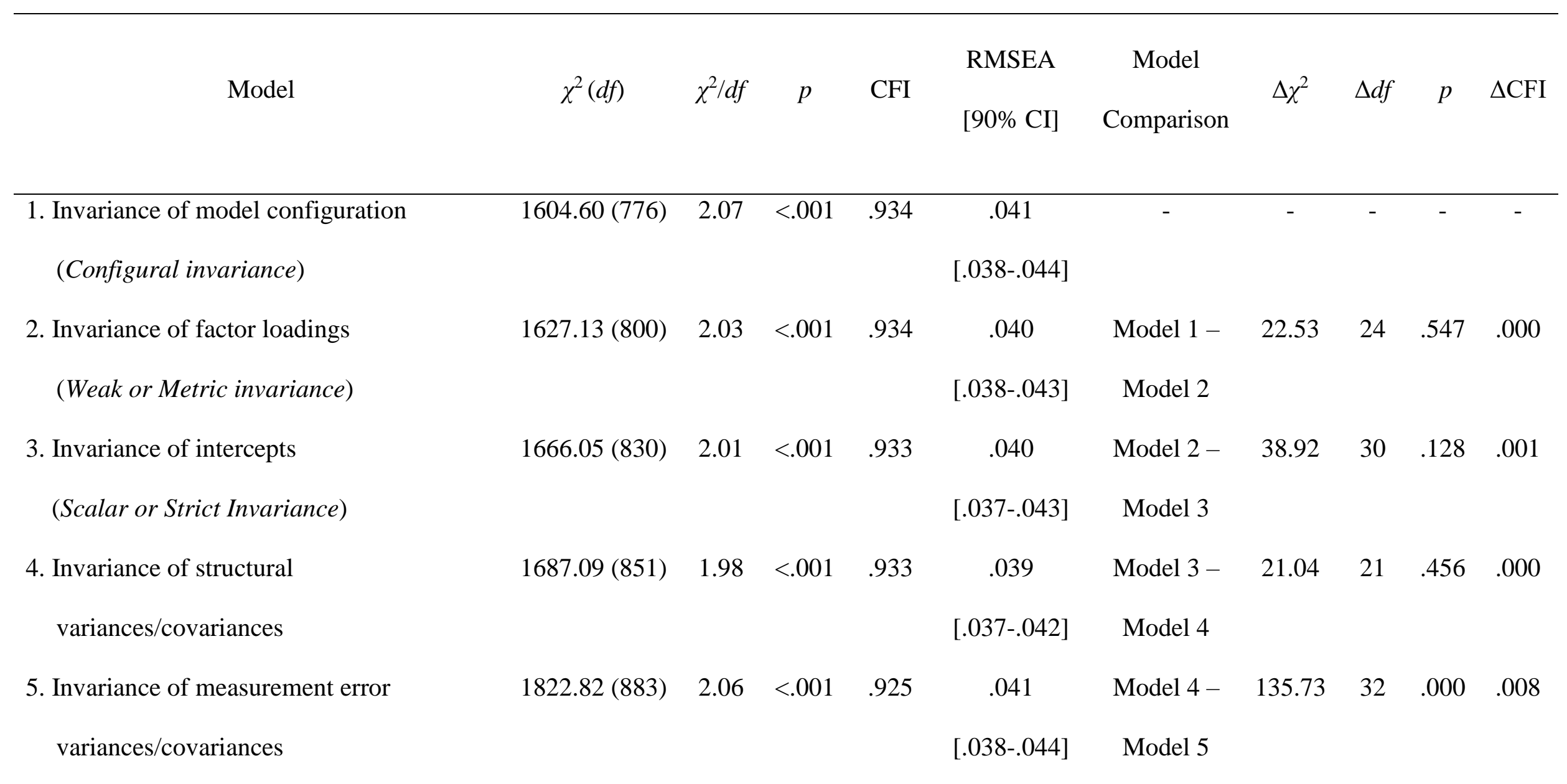

Note $\chi^{2}=$ chi square test; $d f=$ degrees of freedom; CFI = robust comparative fit index; RMSEA = robust root mean square error of approximation; $\Delta \chi^{2}=$ Satorra-Bentler scaled

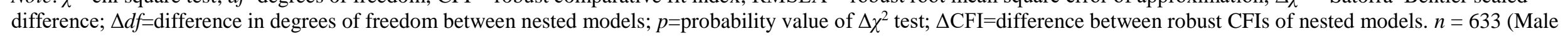
$=229 ;$ Female $=404)$ 
Table 4

Goodness-of-fit statistics for each level of structural and measurement invariance across age levels

\begin{tabular}{|c|c|c|c|c|c|c|c|c|c|c|}
\hline Model & $\chi^{2}(d f)$ & $\chi^{2} / d f$ & $p$ & CFI & $\begin{array}{l}\text { RMSEA } \\
{[90 \% \mathrm{CI}]}\end{array}$ & $\begin{array}{c}\text { Model } \\
\text { Comparison }\end{array}$ & $\Delta \chi^{2}$ & $\Delta d f$ & $p$ & $\Delta \mathrm{CFI}$ \\
\hline $\begin{array}{l}\text { 1. Invariance of model configuration } \\
\text { (Configural invariance) }\end{array}$ & $1457.47(776)$ & 1.88 & $<.001$ & .946 & $\begin{array}{c}.037 \\
{[.034-.040]}\end{array}$ & - & - & - & - & - \\
\hline $\begin{array}{l}\text { 2. Invariance of factor loadings } \\
\text { (Weak or Metric invariance) }\end{array}$ & $1510.98(800)$ & 1.89 & $<.001$ & .944 & $\begin{array}{c}.040 \\
{[.034-.040]}\end{array}$ & $\begin{array}{l}\text { Model } 1 \text { - } \\
\text { Model } 2\end{array}$ & 53.51 & 24 & .000 & .002 \\
\hline $\begin{array}{l}\text { 3. Invariance of intercepts } \\
\text { (Scalar or Strict Invariance) }\end{array}$ & $1644.55(830)$ & 1.98 & $<.001$ & .935 & $\begin{array}{c}.039 \\
{[.036-.042]}\end{array}$ & $\begin{array}{l}\text { Model } 2 \text { - } \\
\text { Model } 3\end{array}$ & 133.57 & 30 & .000 & .009 \\
\hline $\begin{array}{l}\text { 4. Invariance of structural } \\
\text { variances/covariances }\end{array}$ & $1680.06(851)$ & 1.98 & $<.001$ & .934 & $\begin{array}{c}.039 \\
{[.036-.042]}\end{array}$ & $\begin{array}{l}\text { Model } 3 \text { - } \\
\text { Model } 4\end{array}$ & 36.41 & 21 & .020 & .001 \\
\hline $\begin{array}{l}\text { 5. Invariance of measurement error } \\
\text { variances/covariances }\end{array}$ & $1863.82(883)$ & 2.11 & $<.001$ & .922 & $\begin{array}{c}.042 \\
{[.039-.044]}\end{array}$ & $\begin{array}{l}\text { Model } 4 \text { - } \\
\text { Model } 5\end{array}$ & 182.86 & 32 & .000 & .012 \\
\hline
\end{tabular}

Note $. \chi^{2}=$ chi square test; $d f=$ degrees of freedom; CFI = robust comparative fit index; RMSEA = robust root mean square error of approximation; $\Delta \chi^{2}=$ Satorra-Bentler scaled difference; $\Delta d f=$ difference in degrees of freedom between nested models; $p=$ probability value of $\Delta \chi^{2}$ test; $\Delta \mathrm{CFI}=$ difference between robust CFIs of nested models. $n=638$ $($ Younger adolescents $=318$, Older adolescents $=320)$ 
Table 5

Pearson correlations between the Adolescent Time Inventory-Time Attitudes (ATI-TA) subscale scores, and self-esteem and strategic learning subscale scores

\begin{tabular}{lcc}
\hline & Self-esteem & Strategic learning \\
& (high school students) & (college students) \\
\hline Past Negative & $-.43^{* * *}$ & $-.32^{* *}$ \\
Past Positive & $.38^{* *}$ & $.17^{*}$ \\
Present Negative & $-.64^{* *}$ & $-.33^{* *}$ \\
Present Positive & $.58^{* *}$ & $.26^{*}$ \\
Future Negative & $-.47^{* *}$ & $-.43 * *$ \\
Future Positive & $.31 * *$ & $.26 *$ \\
\hline M (SD) & $27.17(5.29)$ & $26.63(5.69)$ \\
\hline Note **p $<.01, * p<.05$. High school students $=382$ College students $=256$
\end{tabular}

Note. ${ }^{* *} p<.01,{ }^{*} p<.05$. High school students $=382$, College students $=256$ 


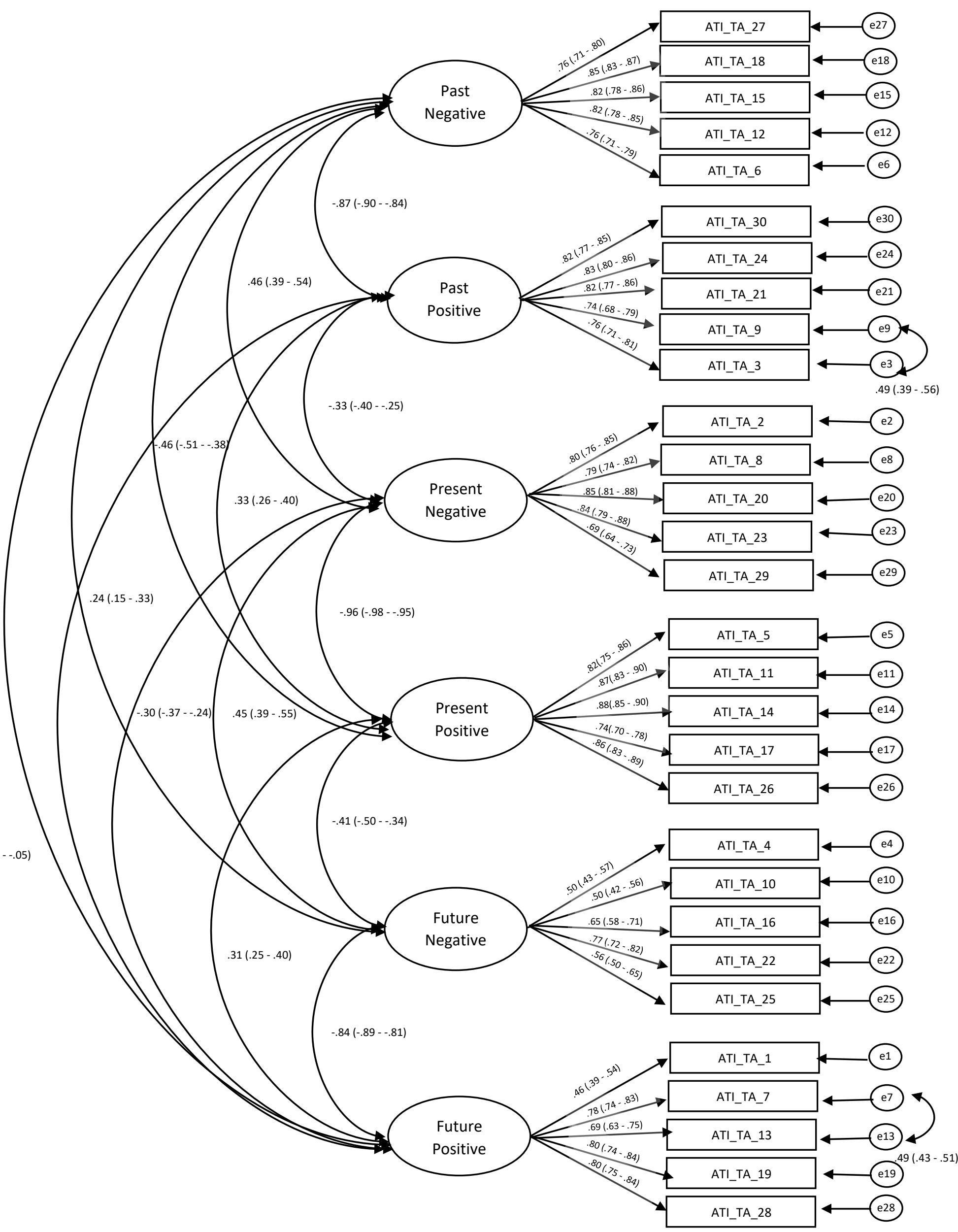

Figure 1.

The six-factor model of the Adolescent Time Inventory-Time Attitudes (ATI-TA) 
Note: standardized parameters, all significant at .001 , with relative $90 \%$ Confidence Intervals, $n=$ 638 